\title{
Simultaneous Determination of Hydrochlorothiazide and Irbesartan from \\ Pharmaceutical Dosage Forms with RP-HPLC
}

\section{SEVINC KURBANOGLU 1 , AYSU YARMAN ${ }^{2}$}

${ }^{1}$ Ankara University, Faculty Of Pharmacy, Department Of Analytical Chemistry, Tandogan, Ankara 06560, Turkey ${ }^{2}$ University of Potsdam, Institute of Biochemistry And Biology, Karl-liebknecht-strasse 25-26,14476 Potsdam, Germany

INTRODUCTION: In this work, a simple and rapid liquid chromatographic method for the simultaneous determination of irbesartan (IRBE) and hydrochlorothiazide (HCT) was developed and validated using reverse phase high performance liquid chromatographic (RPLC) method.

METHODS: Experimental conditions such as; different buffer solutions, various $\mathrm{pH}$ values, temperature, composition of the mobile phase, the effect of flow rate were optimized. RESULTS: The developed RPLC method for these antihypertensive agents was wholly validated and IRBE was detected in the linear range of 0.1-25 $\mu \mathrm{g} \cdot \mathrm{mL}^{-1}$ and HCT was detected in the linear range of $0.25-25 \mu \mathrm{g} \cdot \mathrm{mL}^{-1}$. Moreover, the suggested chromatographic technique was successfully applied for the determination of the drugs in pharmaceutical dosage forms with LOD values of value of $0.008 \mu \mathrm{g} \cdot \mathrm{mL}^{-1}$ for IRBE and $0.012 \mu \mathrm{g} \cdot \mathrm{mL}^{-1}$ for HCT.

DISCUSSION AND CONCLUSION: It is believed that the proposed rapid analyses method of these antihypertensive drugs can be easily used and applied in pharmaceutical companies where the analyses time is important.

Key words: HPLC, Irbesartan, Hydrochlorothiazide, pharmaceutical dosage forms

\section{INTRODUCTION}

Cardiovascular disease causes the death of 17.9 million people annually, which represents nearly $30 \%$ of all global deaths. ${ }^{1}$ Hypertension is responsible for at least $45 \%$ of deaths due to heart disease. Variety of pharmaceuticals, such as angiotensin converting 
enzyme inhibitors, angiotensin-receptor blockers, beta-blockers, diuretics and calcium channel blockers have been applied for the management of hypertension. ${ }^{2}$

Irbesartan (IRBE) (2-butyl-3-[p-(o-1 H-tetrazol-5-yl phenyl)benzyl]-1,3diazospiro[4,4]non-1-en-4-one), is an angiotensin II receptor antagonist, which selectively and noncompetitively binds to the angiotensin II receptor subtype I (Figure 1). It has no affinity for the all receptor subtype 2 , or $\alpha 1$ - and $\alpha 2$-adrenoceptor and serotonergic receptors. ${ }^{3-6}$ IRBE is mainly used for the treatment of hypertension. Furthermore, it may also plays roles in postponement of progression of diabetic nephropathy. It has also a role in the indication for the reduction of renal disease progression in patients with type 2 diabetes, hypertension, and microalbuminuria or proteinuria. ${ }^{3-6}$ Hydrochlorothiazide (HCT), 6-Chloro1,1-dioxo3,4-dihydro-2H-1,2,4-benzothiadiazine-7-sulfonamide, is one of the oldest member of thiazide class of diuretics (Figure 1). Thiazides decrease peripheral resistance by an unknown mechanism and thereby lower blood pressure. HCT is widely used in the form of combination pill with other antihypertensive agents including IRBE. ${ }^{7-9}$

\section{Figure 1 here}

Combined cardiovascular therapy is beneficial, since most of these therapies exploit complementary mechanisms of different acting antihypertensive agents to maximize blood pressure-lowering effects. ${ }^{10}$ In the literature several methods have been described concerning simultaneous determination of IRBE and HCT in pharmaceutical dosage and biological samples using spectrophotometric ${ }^{11-13}$ spectrofluorometric ${ }^{14}$, capillary electrophoretic ${ }^{15}$ and chromatographic methods. ${ }^{16,17}$

In this work, liquid chromatographic method for the simultaneous determination of IRBE and HCT was developed using RP-HPLC. Experimental conditions such as; different buffer solutions, various $\mathrm{pH}$ values, temperature, additives, the effect of flow rate were 
optimized. Moreover, the developed chromatographic technique was successfully applied for the determination of IRBE and HCT in pharmaceutical dosage forms.

\section{EXPERIMENTAL}

\section{Reagents and Chemicals}

Irbesartan and hydrochlorothiazide their dosage forms Karvezide $^{\circledR}$ and Co-Irda ${ }^{\circledR}$ were obtained from pharmaceutical companies. All reagents were in analytical grade and were prepared by doubly distilled water. All experiments were performed at room temperature; all solutions were protected from light and used within $24 \mathrm{~h}$ to avoid decomposition. Chromatographic grade acetonitrile, methanol, hydrogen peroxide, phosphoric acid were used. All other reagents were in analytical grade.

\section{Instrumentation}

Analyses were performed with the Agilent Technologies HP 1100 series (Wilmington DE, USA) LC system equipped with a G1379A degasser, G1311A quaternary pump, 61313 auto injector and G1315B diode array detector. Chromatographic separation was achieved using 60:40 (V/V)ACN:pH 3 phosphate buffer (from $\mathrm{H}_{3} \mathrm{PO}_{4}$ ) as a mobile phase, using an $\mathrm{X}$ Terra $\mathrm{RP}^{\circledR}(250 \times 5 \mathrm{~mm}$ I.D.; $3 \mu \mathrm{m})$ column at a flow rate of $0.8 \mathrm{~mL} \mathrm{~min}^{-1}$, injection value of $10 \mu \mathrm{L}$. The separation was carried out at $30^{\circ} \mathrm{C}$ and the diode array detector adjusted to $226 \mathrm{~nm}$. Before using the mobile phase, the $\mathrm{pH}$ was adjusted with $5 \mathrm{M} \mathrm{NaOH}$, and the mobile phase filtered through $0.45 \mu \mathrm{m}$ Polytetrafluoroethylene membranes using with a vacuum pump and degassed. For the $\mathrm{pH}$ measurements, a pH meter Model 538 (WTW, Weilheim, Germany) was used with a combined electrode an accuracy of $\pm \mathrm{pH}$.

\section{Preparation of Stock Solutions}


Stock solutions of IRBE and HCT $\left(100 \mu \mathrm{g} \cdot \mathrm{mL}^{-1}\right)$ were prepared by dissolving $5 \mathrm{mg}$ of each compound in $50 \mathrm{~mL}$ methanol by ultrasonication $10 \mathrm{~min}$ in ultrasonic bath. The required concentration for the analysis was diluted with the mobile phase.

\section{Analysis of Pharmaceutical Dosage Form}

For both binary mixtures, 10 tablets of $\operatorname{Karvezide}^{\circledR}$ and Co-Irda ${ }^{\circledR}$ were accurately weighed, crushed and finely powdered, separately. From these powders, desired solutions were prepared, sonicated and filtered. The analyzed solutions were obtained by diluting with mobile phase. The content of IRBE and HCT were calculated from the related calibration curves.

\section{System suitability test studies and validation of the analytical method}

The system suitability test parameters such as retention time, symmetry factor, theoretical plate number, selectivity, resolution, and tailing were calculated and compared with the recommended values in USP criteria's. ${ }^{18,19,20}$ Validation of the proposed method was utilized according to ICH Guidelines and USP criteria in terms of precision, accuracy, linear range, limit of detection and quantification values and reported.

\section{Degradation Studies}

It is recommended by $\mathrm{ICH}$ Guidelines to perform degradation studies for the developed assays to show the method is stability indicating. ${ }^{21,22}$ In order to assess the capacity of the proposed method to separate IRBE and HCT from their degradation products, mild and hard conditions like heating in oven $\left(75^{\circ} \mathrm{C}, 3 \mathrm{~h}\right.$ and $\left.24 \mathrm{~h}\right)$, treating the samples with acidic $(0.5 \mathrm{~N}$ $\mathrm{HCl}$ and $1 \mathrm{~N} \mathrm{HCl})$, alkaline $(0.5 \mathrm{~N} \mathrm{NaOH}$ and $1 \mathrm{~N} \mathrm{NaOH})$ solutions, or oxidants $(3 \%$ and $\left.30 \% \mathrm{H}_{2} \mathrm{O}_{2}\right)$, and exposing the UV (254 nm, $3 \mathrm{~h}$ and $\left.24 \mathrm{~h}\right)$ were applied.

\section{RESULTS AND DISCUSSIONS}

\section{System suitability test parameters}


Prior to the validation of the proposed method, system suitability tests such as tailing factor, selectivity, resolution, tailing, theoretical number of plates were calculated reported. The retention factor values IRBE and HCT were calculated and found as 2.08 for HCT and 3.35 for IRBE, other system suitability test parameters are summarized in table 1. It was reported in Table 1, that the proposed method for the determination of IRBE and HCT was suitable related with $\mathrm{ICH}$ guidelines ${ }^{21}$.

Table 1 about here

\section{Method Validation}

Linearity: Linearity of the detector for IRBE and HCT was evaluated by the relation between the peak areas under the corresponding peaks and concentrations of each drug with a correlation coefficient of 0.997 and 0.998 , respectively (Table 2). The repeated injections were performed at each concentration levels. The linear range is in good agreement and have wide linear range values were obtained. For HCT, linear range was obtained between 0.25 and $25 \mu \mathrm{g} \cdot \mathrm{mL}^{-1}$ and for IRBE linear range was obtained between 0.1 and $25 \mu \mathrm{g} \cdot \mathrm{mL}^{-1}$ (Figure 2)

\section{Table 2 here}

Figure 2 about here

Limit of Detection and Limit of Quantification: ICH guidelines proposed several approaches for the determination of limit of detection (LOD) and limit of quantification (LOQ). In this work limit of detection (LOD) and limit of quantification (LOQ) values were calculated related with the relation $L O D=3.3 \mathrm{~s} / \mathrm{m}$ and $\mathrm{LOQ}=10 \mathrm{~s} / \mathrm{m}$ using the standard deviation of response (s) and the slope (m) of the calibration curve. ${ }^{19,22-24}$ LOD, LOQ values were also reported in Table 2, where statistical evaluation of the calibration data were presented. HCT was detected with LOD value of $0.012 \mu \mathrm{g} \cdot \mathrm{mL}^{-1}$ and LOQ value of $0.036 \mu \mathrm{g} \cdot \mathrm{mL}^{-1}$ with the 
propped RP-HPLC method. IRBE was detected with LOD value of $0.008 \mu \mathrm{g} \cdot \mathrm{mL}^{-1}$ and LOQ value of $0.023 \mu \mathrm{g} \cdot \mathrm{mL}^{-1}$ with the propped RP-HPLC method.

Precision: Precision of the proposed method was evaluated by the repeatability studies. Within day and between day repeatability were determined by the injection of three different levels of calibration solutions $(\mathrm{n}=5)$ on the same day and three consecutive days, respectively. Results are expressed by the percentage of relative standard deviation (RSD\%) and shown in Table 2, where statistical evaluation of the calibration data were presented. As seen, there is no significant difference between the values within the within day and between day measurements in mobile phase.

Accuracy: Accuracy is one of the important parameters for the analysis of pharmaceuticals. Real sample applications and recovery studies were performed to show the accuracy of the purposed method. Acceptable results were obtained for Karvezide ${ }^{\circledR}$ and Co-Irda ${ }^{\circledR}$ which contains $150 \mathrm{mg}$ IRBE and $12.5 \mathrm{mg}$ of HCT (Table 3). For the accuracy test, recovery of the method was studied using spiking method. Solutions, were prepared by adding $50 \%, 100 \%$ and $150 \%$ levels standard solutions of the drugs to the pharmaceutical Karvezide ${ }^{\circledR}$ sample (Table 4). The experiment was performed in triplicate and recovery $\%, \mathrm{RSD} \%$, and BIAS\% spiked drugs were calculated. It can be resulted that, using the suggested HPLC method, acceptable recoveries can be obtained with $\mathrm{RSD} \%$ values lower than 1 and recovery values between $98-102 \%$.

Table 3 about here

Table 4 about here

Specificity (degradation studies): Selectivity and specificity is another essential parameter in pharmaceuticals analysis ${ }^{19,21-23}$. Specificity studies were performed by means of degradation studies. Degradation of drugs under mild and drastic stress conditions were given in Table 5, as degradation \%. It can be resulted that, the hard acidic and alkaline conditions hardly affect 
these drugs. In UV and heat degradation these drug can be affected within $3 \mathrm{~h}$ already (Table $5)$.

\section{Table 5 about here}

\section{CONCLUSION}

In the present work, an RP- HPLC method was developed and validated for the simultaneous separation and determination of Irbesartan and Hydrochlorothiazide. The studies were performed for the analyses of Irbesartan and Hydrochlorothiazide from mobile phase. Compared to already published papers we suggest environmentally friendly, green chemistry method for the application to combined drug technology. It is believed that the proposed rapid analyses method of these antihypertensive drugs can be easily used and applied in pharmaceutical companies where the analyses time is important. Moreover, in studies with real samples, or in bioequivalence studies this method may be used. 


\section{REFERENCES}

1. Foley RN, Parfrey PS, Sarnak MJ. Clinical epidemiology of cardiovascular disease in chronic renal disease American Journal of Kidney Diseases. 1998 p. S16-23.

2. Nguyen Q, Dominguez J, Nguyen L, Gullapalli N. Hypertension management: an update. Am Heal Drug Benefits 2010 3(1):47-56.

3. Adams MA, Trudeau L. Irbesartan: review of pharmacology and properties. Can J Clin Pharmacol 2000 7(1):22-31.

4. Ohlstein EH, Brooks DP, Feuerstein GZ, Ruffolo RR. Inhibition of sympathetic outflow by the angiotensin ii receptor antagonist, eprosartan, but not by losartan, valsartan or irbesartan: Relationship to differences in prejunctional angiotensin ii receptor blockade. Pharmacology, 1997;55(5):244-51.

5. Vachharajani NN, Shyu WC, Smith RA, Greene DS. The effects of age and gender on the pharmacokinetics of irbesartan. Br J/Clin Pharmacol 1998;46(6):611-3.

6. Li P, Fukuhara M, Diz DI, Ferrario CM, Brosnihan KB. Novel angiotensin II AT(1) receptor antagonist irbesartan prevents thromboxane $\mathrm{A}(2)$-induced vasoconstriction in canine coronary arteries and human platelet aggregation. JPharmacolExpTher. 2000;292:238-46.

7. Ford $\mathrm{R}$ V. The chinical pharmacology of hydrochlorothiazide. South Med J. $1959 ; 52(1): 40-5$.

8. Kurbanoglu S, Gumustas M, Ozkan SA. Simultaneous estimation and validation of some binary mixtures of antihypertensive drugs by RP-LC methods using two new generation silica columns. J Pharm Biomed Anal 2013;72:198-201

9. Nezhadali A, Mojarrab M. Computational study and multivariate optimization of hydrochlorothiazide analysis using molecularly imprinted polymer electrochemical sensor based on carbon nanotube/polypyrrole film. Sensors Actuators, B Chem. 2014;190:829-37. 
10. Vongpatanasin W. Hydrochlorothiazide is not the most useful nor versatile thiazide diuretic. Curr Opin Cardiol, $2015 ; 30(4): 361-5$

11. Albero I, Ródenas V, García S, Sánchez-Pedreño C. Determination of irbesartan in the presence of hydrochlorothiazide by derivative spectrophotometry. J Pharm Biomed Anal 2002;29(1-2):299-305.

12. Joseph-Charles J, Brault S, Boyer C, Langlois M-H, Cabrero L, Dubost J-P. Simultaneous Determination of Irbesartan and Hydrochlorothiazide in Tablets by Derivative Spectrophotometry. Anal Lett. 2003;36(11):2485-95.

13. Chakravarthy KK, Darak V, Arshad MD, Bharath SA. Development and validation of simultaneous spectrophotometric estimation of Doxycycline and Tinidazole in tablet dosage forms. Pharma Sci Monit. 2010;1(2):534-9.

14. El-Shaboury SR, Hussein SA, Mohamed NA, El-Sutohy MM. Spectrofluorimetric method for determination of some angiotensin II receptor antagonists. J Pharm Anal. 2012;2(1):12-8.

15. Hillaert S, Van Den Bossche W. Simultaneous determination of hydrochlorothiazide and several angiotensin-1I-receptor antagonists by capillary electrophoresis. J Pharm Biomed Anal 2003;31(2):329-39.

16. Coudoré F, Harvard L, Lefeuvre S, Billaud EM, Beaune P, Bobrie G, et al. HPLC$\mathrm{DAD}$ analysis of hydrochlorothiazide and irbesartan in hypertensive patients on fixed-dose combination therapy. Chromatographia, 2011,16;74(7-8):559-565.

17. Vujić Z, Mulavdić N, Smajić M, Brborić J, Stankovic P. Simultaneous Analysis of Irbesartan and Hydrochlorothiazide: An Improved HPLC Method with the Aid of a Chemometric Protocol. Molecules, 2012;17(3):3461-74. 
18. The USP 40. The United States Pharmacopeia, The Official Compendia of Standards. MD, Rockville, USA.; 2017.

19. Michael E. Swartz ISK. Analytical Method Development and Validation. J Pharm Res, 1997;3(4):96.

20. Center for Drug Evaluation and Research (CDER), Reviewer Guidance Validation of Chromatographic Methods, 1994.

21. ICH Guidelines T. Validation of Analytical Procedures, Methodology International Council on Harmonization. Brussels, Belgium; 1995.

22. Chan. CC, Lam. H, Lee YC, Zhang X-M. Analytical Method Validation and Instrument Performance Verification. John Wiley \& Sons; 2004. 105-130 p.

23. Green JM. Peer Reviewed: A Practical Guide to Analytical Method Validation. Anal Chem. 1996;68(9):305A-309A.

24. Ozkan CK, Kurbanoglu S, Esim O, Savaser A, Ozkan SA, Ozkan Y. Simultaneous Determination and Drug Dissolution Testing of Combined Amlodipine Tablet Formulations Using RP-LC. Chromatographia. 2016;79(17-18):1143-51. 
Figure 1. Chemical Structures of A) Irbesartan and B) Hydrochlorothiazide

A<smiles>CCCCC1=NC2(CCCC2)C(=O)N1Cc1ccc(-c2ccccc2-c2nn[nH]n2)cc1</smiles>

B<smiles>NS(=O)(=O)c1cc2c(cc1Cl)NCNS2(=O)=O</smiles> 
Figure 2. Chromatograms of increasing concentrations of Hydrochlorothiazide and Irbesartan

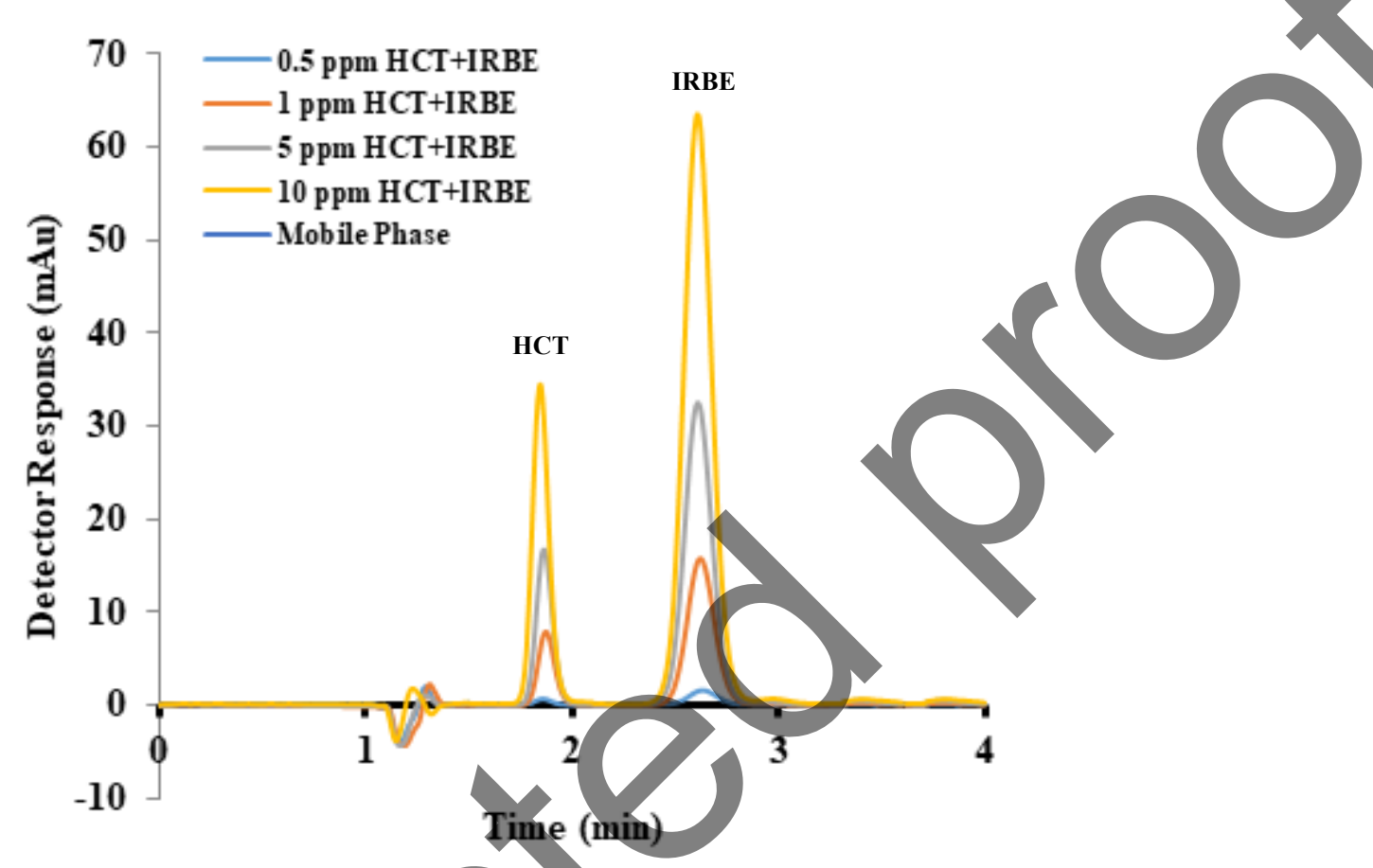


Table 1. System Suitability Tests Parameters

\begin{tabular}{llll}
\hline Parameters & & Recommended \\
\hline Compounds & HCT & IRBE & \\
\hline Retention Time (min) & 1.85 & 2.61 \\
\hline Selectivity & - & & \\
\hline
\end{tabular}

Table 2. Statistical evaluation of the calibration data 


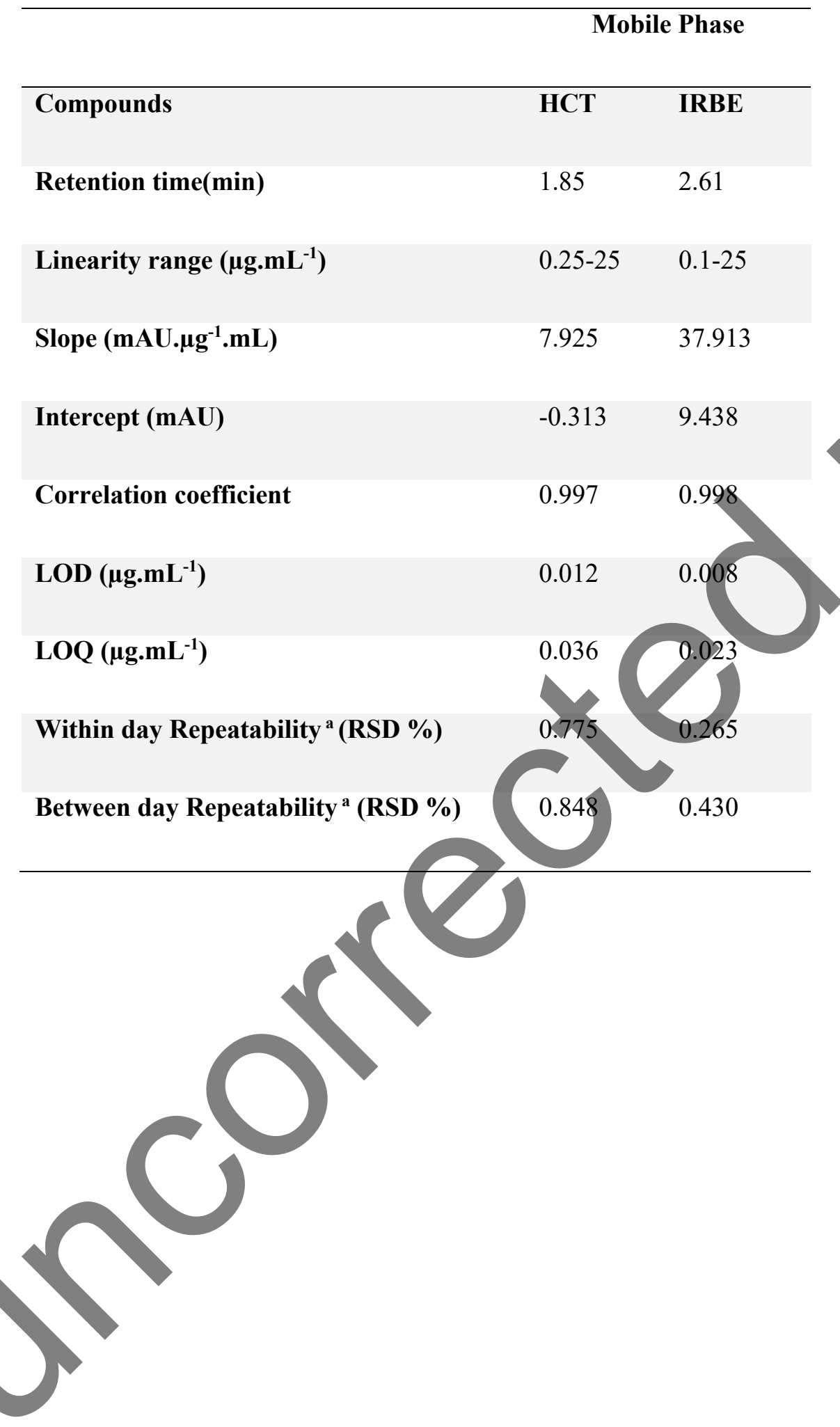

Table 3. Results of tablet analysis from Karvezide ${ }^{\circledR}$ and Co-Irda ${ }^{\circledR}$ 


\begin{tabular}{|c|c|c|}
\hline & HCT & IRBE \\
\hline Label Claimed (Karvezide ${ }^{\circledR}$ mg) & 150.00 & 12.5 \\
\hline Found $^{\text {a }}$ (mg) & 150.59 & 12.42 \\
\hline RSD (\%) & 0.20 & 0.11 \\
\hline $\operatorname{Bias}(\%)$ & -0.39 & 0.63 \\
\hline Label Claimed (Co-Irda ${ }^{\circledR}$ mg) & 150 & 12.5 \\
\hline Found $^{\text {a }}$ (mg) & 149.72 & \\
\hline RSD (\%) & 0.71 & \\
\hline $\operatorname{Bias}(\%)$ & & \\
\hline
\end{tabular}

${ }^{a}$ Each value is the mean of five experiment. 
Table 4. Results of analysis from pharmaceutical dosage form Karvezide ${ }^{\circledR}$

\begin{tabular}{ccccccc}
\hline & \multicolumn{3}{c}{$\mathbf{5 0} \%$ Accuracy } & \multicolumn{1}{c}{$\mathbf{1 0 0} \%$ Accuracy } & \multicolumn{2}{c}{$\mathbf{1 5 0} \%$ Accuracy } \\
\hline & HCT & IRBE & HCT & IRBE & HCT & IRBE \\
\hline Added (mg) & 5.00 & 5.00 & 10.00 & 10.00 & 15.00 & 15.00 \\
Found (mg) & 5.10 & 4.98 & 10.02 & 10.32 & 14.95 & 14.97 \\
Recovery (\%) & 102.07 & 99.73 & 100.16 & 100.33 & 99.64 & 99.81 \\
RSD (\%) & 0.19 & 0.25 & 0.51 & 0.18 & 0.85 & 0.15 \\
Bias (\%) & -2.07 & 0.26 & -0.16 & -0.33 & 0.36 & 0.19 \\
\hline
\end{tabular}

${ }^{\mathrm{a}}$ Each value is the mean of five experiment. 
Table 5. Results of stress conditions by RP-LC in terms of degradation\%

\begin{tabular}{|c|c|c|c|}
\hline & Conditions & HCT & IRBE \\
\hline \multirow{5}{*}{ 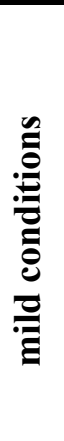 } & HCl (0.5 M) & 43.97 & 77.10 \\
\hline & $\mathrm{NaOH}(0.5 \mathrm{M})$ & 33.16 & 25.15 \\
\hline & $\mathrm{H}_{2} \mathrm{O}_{2}(3 \%)$ & 12.16 & \\
\hline & UV light exposure (3h at $254 \mathrm{~nm}$ ) & 90.18 & \\
\hline & Oven $\left(3 \mathrm{~h}\right.$ at $\left.75^{\circ} \mathrm{C}\right)$ & 95.11 & \\
\hline \multirow{5}{*}{ 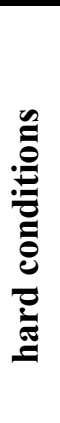 } & HCl (1 M) & 49.98 & 79.69 \\
\hline & $\mathrm{NaOH}(1 \mathrm{M})$ & & \\
\hline & $\mathrm{H}_{2} \mathrm{O}_{2}(30 \%)$ & & 93.91 \\
\hline & UV light exposure (24h at $254 \mathrm{~nm}$ & & 78.46 \\
\hline & Oven $\left(24 \mathrm{~h}\right.$ at $\left.75^{\circ} \mathrm{C}\right)$ & & 87.87 \\
\hline
\end{tabular}


graphical abstract:<smiles>CCCCC1=NC2(CCCC2)C(=O)N1Cc1ccc(-c2ccccc2-c2nn[nH]n2)cc1</smiles><smiles>NS(=O)(=O)c1cc2c(cc1Cl)NCNS2(=O)=O</smiles> 


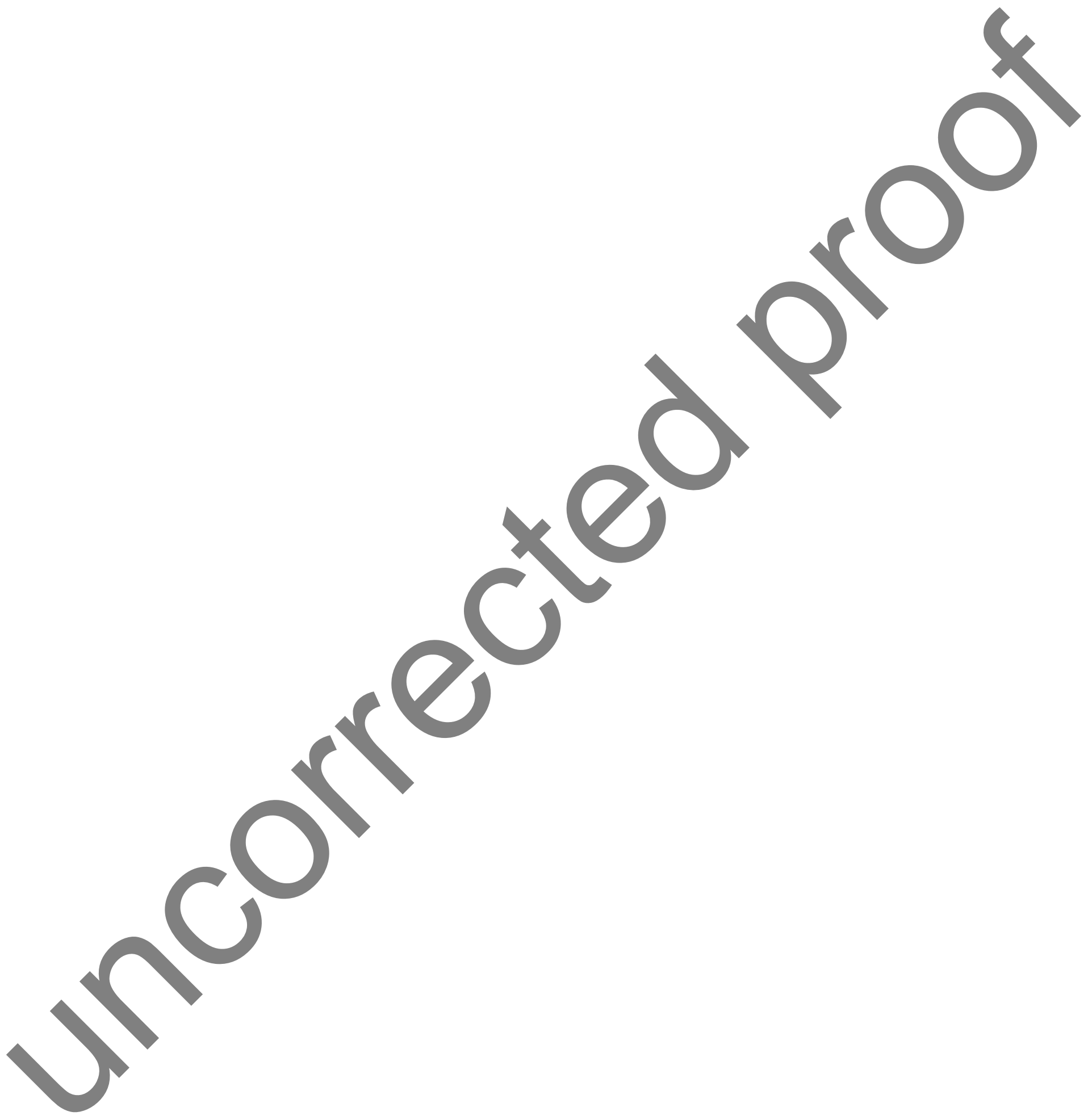

